\title{
La formación (Bildung) literaria basada en la creación de ficción*
}

Literary

Formation

(Bildung) Based on Fiction Writing
Formação

literária (Bildung)

baseada na

criação de ficção

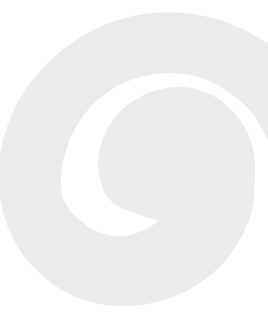

\section{Para citar este artículo}

Saavedra, S. (2020). La formación

(Bildung) literaria basada en la creación de ficción. Folios.51,3-16 doi:10.17227/folios.51-8737

* Este artículo presenta avances de la investigación doctoral La creación literaria como despliegue estético para la formación humana, la cual obtuvo distinción laureada en el Doctorado en Humanidades, humanismo y persona, línea de Antropología pedagógica: persona y formación, de la Universidad de San Buenaventura, Bogotá.

** Doctor en Humanidades, humanismo y persona de la Universidad de San Buenaventura. Magíster en Educación y Licenciado en HuCarodades, Español y lenguas extranjeras de la Universidad Pedagógica Nacional. Actualmente profesor de posgrados de la Facultad de Ciencias Humanas y Sociales e investigador del grupo Tendencias Actuales en Educación y Pedagogía (TAEPE) de la Universidad de San Buenaventura, así como Director del Programa de Años Intermedios del Bachillerato Internacional (iB, Universidad Pedagógica Nacional) en Gimnasio Los Portales.

Correos electrónicos: a.saavedra@|osportales.edu.co - alsaavedra@usbbog.edu.co 


\section{Resumen}

En el marco de la antropología pedagógica, este artículo derivado de investigación propone una formación (Bildung) literaria basada en la escritura como acto de creación ficcional mediante el cual los estudiantes pueden desplegar su facultad estética en cuanto indagación por su condición humana, explorando otras formas de ser y de vivir, como cultivo personal. De esta manera, el taller de escritura trasciende las técnicas de composición y redacción en las que generalmente el aprendizaje marginal de la escritura en la escuela, y se constituye en una propuesta complementaria a la comprensión lectora en que se basan la enseñanza de la literatura, su didáctica específica y su vertiente más significativa, la educación literaria.

\section{Palabras clave}

educación; literatura; creación artística; ficción; educación estética

\section{Abstract}

Within the framework of the pedagogical anthropology, this article derived from a research proposes a literary formation (Bildung) based on writing as an act of fictional creation whereby students are able to display their aesthetic faculty as an inquiry for their human condition, exploring other ways of being and living, making them personal breeding ground. By this means, writing workshop transcends techniques of composition on which the marginal learning of writing in school is based, through a complementary proposal to the reading comprehension on which literature teaching is based, its specific didactics and, its most important trend, literary education.

\section{Keywords}

education; literature; artistic creation; fiction; aesthetic education

\section{Resumo}

No âmbito da antropologia pedagógica, este artigo derivado da pesquisa propõe uma formação literária (Bildung) baseada na escrita como um ato de criação ficcional, através do qual os alunos podem exibir sua faculdade estética como uma investigação da sua condição humana, explorando outras formas de ser e viver, como cultivo pessoal. Dessa maneira, a oficina de escrita transcende as técnicas de composição e escrita nas quais se baseia geralmente; aprendizado marginal da escrita na escola e constitui uma proposta complementar à compreensão de leitura na qua; se baseiam 0 ensino da literatura, sua didática específica e seu aspecto mais significativo, a educação literária.

\section{Palavras-chave}

educação; literatura; criação artística; ficção; educação estética 


\section{Introducción}

La paradoja de la educación literaria radica en que su objeto indaga por la experiencia humana $y$, sin embargo, su enseñanza puede distorsionar ese encuentro vital, agotándose en discursos teóricos, críticos o historiográficos. Aunque esta situación no es exclusiva de lo literario, ninguna otra área puede reprocharse tanto tal contradicción pues "la literatura expresa al hombre en cuanto es humano", mientras "la no-literatura" prioriza un interés de conocimiento determinado por él "en cuanto teólogo, filósofo, cientista, historiador, estadista, político, técnico, etcétera." (Reyes, 2005, p. 18). Si la literatura es una "forma - quizá la más completa y profunda - de examinar la condición humana" (Sábato, 2014, p. 11) y un "escenario simbólico del mundo que posibilita una versión de lo real" (Ferrer, 2000, p. 10), su enseñanza supone espacios escolares donde, además de su estudio lingüístico, artístico, ideológico, textual, cultural y social, se la reconozca como medio para la formación estética - y más ampliamente, para la formación humana configurando desde la ficción otras posibilidades del ser del hombre, en su trasegar por otros mundos posibles.

Desde los aportes de la teoría de la estética de la recepción (Warning, 1989) y de la lectura como proceso transactivo (Rosenblatt, 2002), esta perspectiva experiencial ha sido ampliamente desarrollada para la educación por diversos autores (Larrosa, 2013; Bárcena y Mèlich, 2014; Todorov, 2009; Nussbaum, 2005), reconociendo que el texto solo puede actualizarse mediante el acto de leer, en su encuentro con un lector y sus horizontes de sentido, transformándolo. No obstante, el acto de escribir en cuanto creación de mundos y despliegue estético no ha tenido esta misma atención investigativa $y$, en consecuencia, su introducción sistemática en la educación formal ha sido limitada (Alvarado, 2013; Baquero, 2015; Colomer, 1991; Schaeffer, 2013; Delmiro, 2002; Martínez y Murillo, 2013; Currea et ál., 2017; Ministerio de Cultura, 2011); a excepción de los grados iniciales de escolaridad, en los cuales se da por sentada la relación entre infancia, imaginación, experimentación con la lengua, espontaneidad o juego, en oposición a la sistematicidad del estudio disciplinar propio de los cursos de secundaria.

Esta situación es problemática porque una educación en lo literario resulta incompleta si no aborda procesos de creación que sitúen a los aprendices ante el reto expresivo de la hoja en blanco y sus diversas decisiones de tema, composición y desarrollo, con la conciencia de indagar el mundo (desde su interioridad o perspectiva) y así suscitar una respuesta estética en el posible lector de su texto. En efecto, no conceder espacios de creación para conocer las implicaciones personales, imaginarias, discursivas y sociales, no solo circunscribe la capacidad humana de "producción de estructuras poéticas" como parte de la "competencia literaria" (Bierwisch, 1965), sino que limita el conocimiento mismo de la literatura. Las personas solo podrían experimentarla como espectadores y comentadores, nunca como creadores, al instituirse como una práctica exclusiva de especialistas.

Una revisión a la didáctica de la literatura confirma que esta disciplina ha entronizado el acto de leer durante toda su historia (Ballester, 2015; Dueñas, 2013; Mendoza, 2006; Colomer, 2010a), con excepciones notorias como las propuestas de Rodari (2005) para niños y Demetrio (1999) para adultos en Italia, la escritura sobre uno mismo de Kohan (2002) incluso como terapéutica en España, o los talleres de Pampillo (1982), Alvarado (1981) y su colectivo Grafein en Argentina; entre otros espacios fundamentalmente extraescolares. De hecho, solo trabajos como los del profesor Delmiro (1995; 2002) en el sistema educativo español desde los años ochenta, y Frugoni (2006), rescatando el legado de los mencionados talleres argentinos en las dos últimas décadas, se presentan como apuestas a gran escala por articular la creación literaria a la escuela formal en el contexto hispanoamericano.

En Colombia, su desarrollo ha sido igualmente marginal, de acuerdo con la investigación documental de Martínez y Murillo (2013), y los estudios del Ministerio de Cultura (2011), que evidencian la 
evolución sistemática de la enseñanza de la escritura creativa solo en ámbitos extraescolares. A pesar de esto, sobresalen apuestas individuales como los talleres curriculares en el INEM Baldomero Sanín Cano de Manizales, liderados por los profesores Jaramillo y Manjarrez (1998) en la década de los noventa; los talleres de Escritores en la Primaria del Colegio Granadino de esta misma ciudad gracias al empeño del profesor Yamasaki; la presencia artística permanente en diversos IED de Bogotá como Antonio José Uribe, El Rodeo, La Joya, Los Alpes, Pantaleón Gaitán o San Isidro, como parte del proyecto Pájaros de tinta de acuerdo con el convenio entre la Corporación Comunicar e Idartes desde 2015; o el Taller libre de creación literaria desarrollado en el Colegio Mayor de Barranquilla y del Caribe; solo por mencionar algunos esfuerzos escolares sostenidos en este sentido. Igualmente, los reconocidos talleres de escritura creativa y grupos literarios, nacidos de iniciativas particulares desde centros culturales (Fundación Fahrenheit 451, Centro de desarrollo artístico Compaz, Corporación Comunicar o Liebre lunar en Bogotá; Fundación La Cueva en Barranquilla; Rayuela en Cúcuta; Comfandi y la Fundación Escribir no muerde en Cali; Escuela Permanente de poesía de Medellín, por ejemplo) o universidades (grupo de poesía Ulrika y el grupo de investigación HIMINI en la Universidad Pedagógica Nacional, taller de escritura creativa "Te cuento" de la Universidad del Norte, taller biblioteca de la Universidad del Valle, Alejandría en la Universidad Pedagógica y Tecnológica de Colombia en Tunja, laboratorio de escritura creativa de la Universidad Nacional Abierta y a Distancia, entre otros surgidos en instituciones de Educación Superior como la Universidad del Valle, EAfIT, Católica, El Rosario, Universidad Nacional de Educación a Distancia de Cartagena o la Universidad Autónoma de Occidente).

Mención especial merecen los programas de pregrado y posgrado de reciente creación en el país. La Universidad Central, pionera con su taller de escritores TEUC, fundado en 1981, lanzó en 2008 una especialización al respecto, y hoy ya cuenta con maestría y carrera profesional en Creación Literaria. Asimismo, la Universidad Nacional de Colombia inauguró en 2007 la primera Maestría en Escrituras Creativas. A estas abanderadas se han sumado en años más recientes universidades como la EAFIT y el Instituto Caro y Cuervo con maestrías homólogas. Igualmente, un gran número de instituciones de educación superior han visto en esta modalidad anglosajona un espacio interesante de cursos optativos, diplomados o de educación continua para los miembros de su comunidad. Como si esto fuera poco, los esfuerzos estales en los ámbitos local, regional y nacional han generado estímulos a través de la Red Nacional de Escritura Creativa (RELATA), puesta en marcha desde 2006 con este fin, y que en 2018 ya contaba con 56 talleres en 24 departamentos.

Con todo, estos no dejan de ser procesos externos al currículo oficial del bachillerato y su énfasis lector, como lo evidenció el Estado de arte sobre la relación entre creación literaria y formación humana en trabajos de investigación referidos a la educación secundaria (2017) desarrollado en la Especialización en Didácticas para Lecturas y Escrituras con énfasis en literatura de la Universidad de San Buenaventura. Dicho estudio confirmó la escasez de propuestas en este sentido, y la manera en que los trabajos existentes realmente se han interesado más en la apropiación de rudimentos lingüísticos y la ejercitación de habilidades comunicativas que en el sentido formativo de la creación para sus participantes (Currea et ál., 2017). También en investigaciones en aula (Saavedra, 2011; 2013; 2017), se ha evidenciado este estado marginal de la creación en el bachillerato, pues la producción textual generalmente se ejecuta en respuesta a lo leído (comentario de texto) o para reproducir saberes disciplinares o de uso de la lengua. Tal cosificación del código escrito omite sus propósitos de expresión, creación o invención para configurar otros mundos reales, probables y posibles.

Por esta razón, desde una perspectiva antropológica-pedagógica se plantea otra vía educativa que profundice en este campo de estudio, la literatura, ahora desde su sentido originario, la poesía, en cuanto expresión humana para crear lo inexistente. Desde Heródoto, la poiesis se refiere a la creación 
como acción pura o proceso activo, que recoge la aún no realización, la posibilidad de crear algo distinto a partir de materiales preexistentes. Se trata de la capacidad creadora en general que transforma el no-ser en ser. Esta vía constituye entonces una posibilidad para vincular la experiencia literaria a procesos auténticos de creación mediante la escritura y, de esta manera, acercar a los estudiantes al propósito fundante de este discurso que ha acompañado a la humanidad en su trasegar por el mundo.

\section{Literatura y creación: discurso y exploración de lo humano}

Aun en sus diferencias contextuales y conceptuales, poéticas clásicas como las de Aristóteles (2007) u Horacio (2012) y, especialmente, teorías literarias fundantes como las de Warren y Wellek (2009), Kayser (1992) o Aguiar e Silva (2011), y estudios más recientes como los de Garrido (2000), Eagleton (2002) o Llovet (2012) coinciden en abordar la composición del texto (componente artístico de la obra) debido a que su componente estético escapa del discurso teórico al ser una experiencia humana contingente. Si bien estas obras se despliegan desde la definición de poesía, literatura o literariedad, sus elaboraciones de estos conceptos reconstruyen la complejidad y lo inasible de un discurso que atañe por igual a aspectos y propósitos personales, sociales, históricos, culturales, artísticos, estéticos y políticos; cuyo material es el lenguaje (también creación humana, simbólica, contingente, objeto de vicisitudes y funciones ideológicas específicas) en la mayor conciencia de sí mismo como signo (función estética) para aprovechar su carácter expresivo y pragmático e indagar las experiencias particulares de ciertos personajes en momentos hipotéticos específicos, en tanto ficción. Allíla idea de lo bello o el arte, referido a su forma o composición, manifiesta su fundamento en cuanto re-presentación de la realidad a través de mundos posibles, por lo cual no se le puede exigir una "verdad" de hechos o datos verificables objetivamente, pero sí configura un conocimiento estético, de acercamiento a la vida humana, al constituirse, como cualquier arte, en una experiencia sensible, racional y analógica, con sus repercusiones estéticas y éticas respectivas (lo dulce y lo útil que desde Horacio ha sido la vía de encuentro y discusión para determinar el valor de la literatura).

Entre estas dificultades para establecer una definición precisa, Warren y Wellek concluyen sus reflexiones sobre la naturaleza y funciones de la literatura con uno de los aportes más significativos de su Teoría literaria: "la poesía tiene muchas funciones posibles. La primera y principal es la fidelidad a su propia naturaleza" (2009, p. 49), una vez han establecido sus profundas relaciones con todos los ámbitos de la vida social y personal, su complejidad, sin poder delimitarla a una naturaleza concreta, asible, única. Esto no debería entenderse como una falacia, pues precisamente comprender algo como indefinible manifiesta su importancia y sentido en la configuración humana porque aborda las contingencias mismas de la existencia del hombre, su historia, tal como advirtieran Bárcena y Mèlich (2014). Es más, siguiendo estos juegos del lenguaje, se podría decir que no se puede definir lo indefinible: lo conmensurable es un hombre abstracto, ideal, planteado por algunos sistemas teóricos, científicos o filosóficos; pero la persona concreta, individual, en continua formación, inconmensurable, irrepetible, abierta a las posibilidades de la existencia desde sus circunstancias específicas, de interés para la antropología pedagógica (Hamman, 1992; Londoño, 2010), es la que se despliega en el discurso literario, así sea a través de los mecanismos de la ficción.

Como lo plantea Cárdenas (2004), los elementos constitutivos de la literatura son la poesía, el arte, el lenguaje y el mundo.

[A través de ellos, las personas participan en] un ejercicio creativo y lúdico de la sensibilidad, la imaginación y el intelecto [que constituye a su vez] una manera de sentir, imaginar y conocer el mundo, con el fin de darle forma estética, poner en obra lo que antes no existía en la realidad y representarlo de manera sugerente (p. 18).

A partir de esta concepción estética se efectúa la composición textual mediante técnicas y procedimientos expresivos que forjan el carácter artístico de lo literario, como esa forma particular de la obra 
cuya intencionalidad es producir una respuesta estética en el lector. De hecho, este autor instituye los dos ámbitos de interés para una pedagogía de la literatura: el mundo construido (estética) y el texto producido (arte). Sin embargo, la escuela muchas veces ha entronizado en sus prácticas de lectura $y$ en aquellas marginales de escritura el segundo ámbito, quizá por ser más proclive al control y la medición. Así, desarrolla discursos analíticos para proporcionar estructuras y elementos en los que se basa su composición, obviando el proceso de crear mundos. De esta manera, se tergiversa esa "fidelidad a su propia naturaleza" reclamada por Warren y Wellek (2009) para la literatura, pues si esta puede auscultar la totalidad de ámbitos del mundo y de la vida (lo que han sido e, inclusive, lo que podrían ser) es precisamente porque es un discurso sobre la condición y la complejidad de lo humano.

En respuesta, aquí se propone una formación (Bildung) literaria que enfatiza ese ámbito estético de sensibilidad e inventiva para crear mundos (poiesis) que convoquen tanto la identificación con universales humanos desde experiencias particulares, como la manera en que su contraste con la realidad incita el pensamiento divergente, subversivo, propio de la literatura, como otras posibilidades de existencia. Con este propósito, la creación parte de lo conocido (el lenguaje común, la experiencia cotidiana) para conectar con lo desconocido, con el misterio de ese lenguaje y esa existencia (Béguin, 1997). Y es en esta búsqueda de sentidos que se configura el despliegue estético en el lenguaje como posibilidad de formación para cualquier persona que enfrenta tal reto creativo.

\section{Formación (Bildung) y creación literaria: despliegue personal en el lenguaje}

En la tradición pedagógica alemana, la formación (Bildung) refiere al despliegue espiritual que realiza cada persona para alcanzar su plenitud humana, diferenciándose conceptualmente de la educación (Erziehung). Según estudios contemporáneos sobre esta distinción planteada por Herbart (Garcés y Runge, 2011; Horlacher, 2014; Fabre, 2011; Ipland, 1999), la educación posibilita una experiencia significativa en el nicho social al cual el niño llega al nacer, desde su contexto familiar hasta la escuela, atravesando todos los ámbitos externos que procuran acogerlo y legarle una manera de ser y de vivir. Por su parte, la formación es el desbordamiento interior de cada persona, que evidencia una respuesta propia - conciencia, voluntad, toma de postura, autonomía- y que, en cuanto tal, trasciende lo propuesto por tales acciones educativas para construir un sentido personal. Así, no se trata de un producto predeterminado de la educación, sino de un efecto que la persona a la que se pretende educar lleva a cabo por cuenta propia. La formación se refiere entonces "al trabajo sobre sí mismo para forjar el hombre al que se aspira, ese que solo se es en potencia, contenido en uno mismo como deseo y posibilidad, pero que debe desplegarse, desbordarse, convertirse, transformarse" (Saavedra, 2017, p. 201).

En este proceso, el lenguaje como mediación fundamental del anthropos, así como instituye parámetros culturales que lo orientan en el mundo, le permite adquirir conciencia de sí, proyectando su existencia a través de realidades hechas de palabras. Tan solo la presunción de un pasado o un futuro - irrealidades solo existentes en la mente del hombre gracias al lenguaje- le permite comprenderse a sí mismo y proyectarse, de acuerdo con su apertura al mundo.

Lo que aún no es forma parte importante de lo que el ser humano es. En efecto, en una medida no pequeña, todo hombre es lo que ha llegado a ser (a partir de lo que fue y ya no es) y lo que aspira a ser y todavía no ha logrado ser. La descripción de esos dos sectores de lo irreal forma parte de la realidad de lo que cada ser humano es. (Barrio, 2010, p. 114).

Esto ilustra, sin duda, una manera en la que el lenguaje constituye la formación, esto es, la humanización, en cuanto desbordamiento de sentidos por parte del anthropos. En este sentido, Vargas et ál. (2010) han actualizado la concepción tradicional de formación (Bildung) desde la fenomenología y la antropología pedagógica, resaltando el papel fundamental del lenguaje: "se trata de que el ser alcance la plenitud de su despliegue mediante su propia exposición por vía de, a través de y en el lenguaje. En esta 
perspectiva la formación no puede ser una estrategia de imposición, de instrucción, de modelamiento, sino en la medida que el ser se expone propicia un salto, un paso fuera de sí" (Vargas et ál., 2010, p. 9). En consecuencia, la escritura es concebida como un registro del proceso de significación que cada persona puede realizar en cuanto despliegue de su propia existencia. Aun más, las aperturas semánticas, imaginarias y experienciales que posibilita la literatura en esta práctica se articulan a la formabilidad latente en cada persona, como rasgo espiritual para transformarse, configurando un escenario de formación basado en la creación literaria.

Escribir con intencionalidades estéticas para realizar algo que pueda ser considerado literatura es crear mundos posibles en tanto nuevas alternativas de existencia; significa experimentar otras dimensiones de la "realidad real", la cual puede resultar más vívida, enriquecida, una vez es narrada o poetizada, pues el primer contacto con los acontecimientos siempre es limitado a sus contingencias. $\mathrm{Si}$ la formación es una indagación de uno mismo, no desde lo que se es, sino desde lo que se podría llegar a ser, la creación de mundos de ficción, alternos al real, a partir del único material que posee quien escribe, su propia existencia, configura un viaje interior para buscar en uno mismo lo que hasta ahora no ha sido. (Saavedra, 2017, p. 199).

La propuesta didáctica teórico-formativa aquí presentada especifica esta relación entre el lenguaje y la formación, ahora en la interacción entre la ficción y el despliegue de sentido personal. Más específicamente, evidencia los efectos formativos de la ficcionalización literaria en la búsqueda de sentido de cada persona a través de la construcción de lo inexistente que proyecta de sí mismo o su mundo. Crear ficción es explorar posibilidades de existencia a partir de lo que cada hombre entiende que es y sus proyecciones particulares libres de represiones, gracias al juego del "como si"; de lo que podría o debería ser, pero no es. En otras palabras, experimentar creativamente con la misma palabra que instituye "lo real" significa indagar y cuestionar eso que se considera cierto de la propia existencia, abriendo puertas a nuevos modos de ser. Esta práctica de escritura constituye entonces un escenario educativo propicio para suscitar la conciencia sobre el papel determinante del lenguaje en la configuración del hombre, su sociedad y su cultura. Igualmente, para interpelar a los estudiantes sobre lo instituido como "real", leyendo críticamente, como "hechura" o artificio, cualquier tipo de discurso.

Por lo demás, si bien es necesaria la correlación entre la recepción y la creación literarias para consolidar la formación en este campo, la prevalencia del proceso de lectura en el devenir de la didáctica de la literatura y, sobre todo, cierto abordaje instrumentalizado del que le ha costado escapar demanda pensar esta disciplina también desde la escritura. A través del concepto clásico de poesía como poiesis (creación) en lugar de la idea de la literatura (del latín littera) limitada a algo capaz de ser leído. El primero, marginado de la secundaria en la actualidad, podría incitar el despliegue espiritual de la formación (Bildung) de acuerdo con la facultad estética de las personas, en tiempos en que el segundo reproduce ciertas prácticas objetivadas, como develamiento de discursos paraliterarios que se institucionalizan en las pruebas censales. En suma, se trata de una alternativa para afrontar la cosificación a la que siempre está expuesto cualquier componente del sistema educativo, lo que enriquece los procesos formativos desde la creación auténtica y singular de las personas.

\section{De la educación a la formación (Bildung) literaria}

El devenir histórico de la didáctica de la literatura confirma que la creación nunca ha adquirido protagonismo debido a que la lectura se ha considerado el núcleo inexcusable de la educación literaria (Dueñas, 2013; Colomer, 2010a; 2010b). Según Colomer (2010b), primero como práctica de análisis y glosa para dominar el discurso oral y escrito (sermón eclesiástico, discurso político) en el marco de la retórica y, más adelante, como actividad de lectura individual, en los orígenes de la escuela de masas y su proyecto alfabetizador, cuyo objetivo esencial fue la decodificación y la memorización de textos. 
Debido al espíritu romántico y nacionalista del siglo XIX, "la historiografía literaria seleccionó y sancionó los autores y las obras clave del patrimonio nacional y creó la conciencia de un pasado y un bagaje cultural que debían ser difundidos y exaltados durante la etapa escolar" (Colomer, 2010b, p. 2). En este proceso, la retórica y las obras clásicas cedieron su lugar a la lectura de las literaturas nacionales como ejercicio interpretativo, apelando a los contextos históricos que representaban en cuanto documento cultural, y haciendo de la lengua literaria el modelo para el aprendizaje y el enriquecimiento del lenguaje.

Ya en el siglo xx, debido a la eclosión de diversas corrientes lingüísticas, se utilizó la teoría literaria para dar rigor científico a los métodos interpretativos, basados en los intereses del estructuralismo, el formalismo ruso y el Círculo de Praga, difundidos oficialmente para la educación a partir del Congreso de Cérisy-La Salle de 1969, dirigido por Todorov y Doubronski. Desde esta perspectiva se enfatizó en asuntos como la literariedad, la desviación de la norma lingüística, la función poética o la manera en que la forma de la obra se relaciona con una estructura ideológica. En otras palabras, se abordaron las relaciones entre texto y contexto, pero en ciertas ocasiones de manera inmanentista y mecanizada.

Como estas prácticas no suscitaron necesariamente el desenvolvimiento comunicativo de los estudiantes en el encuentro con lo literario, en las tres últimas décadas se ha configurado la didáctica de la literatura como interdisciplina derivada de los estudios pragmáticos y discursivos, particularmente la estética de la recepción (González y Caro, 2009), potenciando aspectos como la expresividad, la funcionalidad y la intención dentro de un contexto auténtico. De acuerdo con Colomer (2010a), esta configuración didáctica determina el paso de la enseñanza de la literatura a la educación literaria, pues transforma su enfoque en la obra por el del discente en relación con el texto, esto es, implicar la apelación al lector. De ahí han derivado las propuestas recientes de animación lectora, lectura por placer y relación con otros sistemas simbólicos, con el fin último de consolidar tal relación entre experiencia literaria y experiencia vital.
Sin duda, la educación literaria es en la actualidad la vertiente más significativa de esta didáctica específica, centrada aun más en la recepción de lectores particulares desde sus motivaciones y construcciones de sentido a partir de los avances de la semiótica y las gramáticas del texto de autores como Bajtin, Lotman (2011) o Eco (1994), que comenzaron a popularizarse en las líneas de investigación educativa desde la década de los ochenta. En el marco del enfoque comunicativo, su propósito ha sido el desarrollo de la "competencia literaria" en tanto uso social de la comprensión y la producción textuales para construir sentido, situación que privilegia el aprendizaje autónomo y la exploración personal.

Como parte de esta evolución disciplinar, la propuesta de una formación (Bildung) literaria contribuye a la didáctica de la literatura, pues recobra la correlación imprescindible entre los actos de leer y escribir para que los estudiantes no experimenten las obras solamente como receptores y comentadores, sino también como creadores de mundos posibles y productores de textos auténticos. Por ello, junto a las prácticas lectoras ya afincadas en la escuela, prioriza el abordaje de la creación, con el fin de experimentar con el lenguaje y sus procesos de ficcionalización. De esta manera, busca equilibrar la frecuencia de estas prácticas escolares, dado que accede al fenómeno literario por el camino menos transitado en las aulas: la escritura, en su versión menos instrumentalizada: la creación. Esto supone un cambio significativo: de la educación literaria basada en la recepción textual y el acervo cultural hacia una formación (Bildung) literaria basada en la escritura como creación ficcional, incluyendo su ámbito artístico de estrategias de composición y aspectos formales, pero cuyo énfasis está en su ámbito estético de indagación por lo humano, de creación de mundos posibles desde la sensibilidad, la imaginación y la razón, como parte de la realización personal.

Como esta idea puede alarmar a maestros y expertos en este campo, es necesario aclarar que no se pretende prescindir de la lectura como el acto por antonomasia que configura, enriquece y consolida la educación literaria. Todo lo contrario: esta propuesta supone diversificar y fortalecer el proceso lector para 
que no solo atienda a demandas de comprensión e interpretación, sino también de creación y escritura orientados a propósitos comunicativos auténticos. Leer para escribir. Leer como escritor. Leer desde la escritura para entender los modos en que los autores afrontan ciertos retos vitales y discursivos al forjar sus obras. En este sentido, la teoría es fundamental para comprender el fenómeno literario de manera profunda, así como la crítica y la historia permiten acceder a las obras y valorarlas, gracias a que amplía perspectivas de los textos y de la vida misma en el marco de las humanidades. En fin, la literatura siempre ha sido uno de los contenidos y continentes del acervo y la transformación cultural sin lectura sería imposible conocer y experimentar las formas que ha adoptado en diversos lugares y épocas.

\section{Propuesta didáctica teórico- formativa: la asignatura Ficciones}

Esta formación (Bildung) literaria se ha puesto en práctica mediante Ficciones, un taller de escritores para estudiantes de bachillerato que ha buscado explotar lo formativo (Gehalt) de cada contenido (Inhalt), en tanto propuesta didáctica teórico-formativa (Klafki, 1986; 1991; Runge, 2008) basada en los procesos leer para escribir, escribir para crear mundos y crear mundos para formarse. Desde su apertura en 2016, esta electiva ha acogido a 105 estudiantes de grados décimo y undécimo de los colegios Gimnasio Los Portales, Gimnasio La Montaña y San Mateo Apóstol de la ciudad de Bogotá, Colombia, como parte del programa interinstitucional Trion. Su particularidad radica en la exploración consciente del entramado lingüístico como material simbólico, metafórico, retórico y estético de la realidad, cuyos productos ficticios (mundos autorreferenciales) y facticios (con la realidad convenida socialmente como referente) amplían la experiencia vital de autores y lectores desde lo sucedido hasta lo posible, de acuerdo con la capacidad imaginativa del anthropos.

Además de seguir la tradición de los talleres literarios ampliamente desarrollada en contextos extracurriculares y trasladada de manera incipiente a las aulas (Vargas, 2011), Ficciones retoma para el currículo oficial la idea del taller como método de enseñanza en la escuela (Alvarado, 2013). Este espacio de encuentro con lo humano para experimentar, analizar y discutir las creaciones textuales de cada uno de los participantes, aborda de manera articulada e iterativa cuatro componentes fundamentales para la producción escrita: la indagación conceptual de algún tema específico sobre el proceso de escribir o alguna tipología textual en particular; un espacio de recepción y análisis de textos en cuanto modelos para evidenciar las estrategias, propósitos y herramientas discursivas de diversos autores; el momento central, desplegado la mayor parte del tiempo de clase, en el cual se escriben, corrigen, depuran, precisan y refinan los escritos desde la conciencia de la creación como una alternativa para configurar lo que se considera real; y el espacio de diálogo, corrección, valoración, evaluación y realimentación con el profesor y entre compañeros con el fin de construir conocimiento de manera colaborativa, desde el juicio crítico sobre los escritos.

El sentido del taller es aprender a escribir escribiendo, en cuyo despliegue el profesor interactúa con los estudiantes cuestionándolos sobre sus decisiones en cada uno de los componentes de su texto, desde elecciones temáticas hasta estructurales en los ámbitos tanto locales como globales, lo que propone otras posibilidades de realización. Ante todo, el profesor valora y critica los mundos creados por el aprendiz, su modo de concebir y comunicar ciertos aspectos de la realidad para formar su conciencia discursiva como autor.

La comunidad de lectores y escritores que se configura en el aula, además de afrontar y compartir retos creativos, evidentemente teje relaciones con respecto a su manera de ver el mundo, como personas con intereses y perspectivas diversos, constituyendo un potente ambiente de aprendizaje del código escrito ante desafíos comunicativos reales - y de formación - al implicar la exploración de la propia existencia como material de tales obras. Al final del semestre, cada participante consolida un portafolio de escritor con los textos más significativos que ha creado durante las clases, los cuales 
han pasado por múltiples procesos de valoración, revisión y reconstrucción de acuerdo con rúbricas que plantean el criterio discursivo fundamental (cumplir el propósito comunicativo de cada proyecto de escritura), así como los criterios de composición (coherencia, precisión, cohesión, pertinencia, claridad y aspectos formales) a la luz de modelos diversos de textos lingüísticos y no lingüísticos, que logran adentrarlos en estructuras y contenidos alternativos, con el fin de generar efectos creativos; por ejemplo, la escritura experimental de Calvino y Queneau, o las peculiaridades de la minificción, junto a otras "formas clásicas", siempre diversas, de los géneros y las tipologías textuales.

En suma, el acto de escribir no es visto en Ficciones como un ejercicio de composición y redacción correctas, dependiente de grandes cantidades de texto; de hecho, no hay límites ni mínimos de palabras, siempre y cuando el texto cumpla su propósito comunicativo a juicio de la comunidad de lectores y escritores. Tampoco como un cúmulo de reglas gramaticales para formalizar ideas por escrito, cuyo resultado hubiese sido el mismo en la oralidad. Por el contrario, se experimenta la escritura como un proceso, en sí mismo, de pensamiento, imaginación y sensibilidad, que implica transformaciones en lo que se piensa, se imagina o se siente sobre algún aspecto del mundo en el desarrollo de esta tarea de significación. En tal construcción discursiva está la voz del estudiante haciéndose presente ante su vida, configurada en un mundo "como si", que abre la puerta para el juego de la interpretación y los efectos estéticos.

\section{Estética y ficción: "mundos posibles" para la formación humana}

La propuesta didáctica teórico-formativa desplegada en este taller de escritores plantea, en última instancia, la conexión entre estética y ficción. Como afirma Vargas Llosa (1998, 2002), si bien la literatura es ficción y no la verdad fáctica que pretende la ciencia, "es una mentira que encubre una profunda verdad" (Vargas Llosa, 1998, p. 13). Quien escribe accede de un modo alternativo, singular y participativo en la construcción de lo real, y lo comparte con sus lectores. Así, la escritura,

[...] da orden y sentido a esa existencia que fluye de manera inconmensurable y caótica, presentando un reflejo analizable - y quizá mejor experimentable - de lo que somos como especie, de lo que nos une como personas; esos universales que exploran nuestra condición humana desde nuestras singularidades (Saavedra, 2017, p. 206).

¿Cuál sería entonces la incidencia formativa de crear ficciones? Larrosa (2013) en su lectura del concepto formación en Nietzsche, quien lo resume con el verso de Píndaro "llega a ser el que eres", evidencia que esta es un proceso de invención de la propia existencia, el cual implica, para cualquier persona, acciones similares a las que supone, para un autor, la creación de mundos posibles. El recorrido de este autor por la filosofía, especialmente de la historia y del espíritu de amplia tradición neohumanista desde la Ilustración alemana; la pedagogía, en torno al papel formativo de las humanidades; $y$ la narrativa, en cuanto Bildungsroman o novela de formación, basada en la realización personal de sus protagonistas justamente le permite acentuar el carácter creativo de la formación.

Eso que somos y que tenemos que llegar a ser no es ya ni sujeto ni objeto, no es una "realidad" de ningún tipo, ni subjetiva ni objetiva, no es ni siquiera una "idea" que tendríamos que "realizar", sino que está claramente del lado de la invención. El hombre es un animal de invención, y las distintas formas de conciencia no son sino productos de esa función inventiva [...] El "llegar a ser lo que se es" no está ya del lado de la lógica de la identidad, del autodescubrimiento, del autoconocimiento o de la autorrealización, sino del lado de la lógica desidentificadora de la invención (Larrosa, 2013, p. 127).

Tal proceso inventivo encuentra un asidero de múltiples posibilidades en la creación de mundos de ficción que, más allá de representar lo que es, refieren a lo que podría ser. En tales opciones de existencia, estos mundos posibles interpelan a cada persona en su despliegue espiritual para llegar a ser lo que son. Así, la definición aristotélica de que la poesía es más 
doctrinal y filosófica que la historia por no referir solamente a lo acontecido, sino a lo que debería o podría haber sucedido, plantea para la actualidad de cada persona que lo poético "es el único medio humano que podríamos vislumbrar que daría la armonía entre nuestro ser y todo lo que éste no es [...] [como]una manifestación de lo que llamamos nuestra vida interior" (Béguin, 1997, p. 9).

De esta manera, la ficción no se limita a una representación de la realidad sino que, como lo plantea López Quintás (1991; 2000), “plasma ámbitos” en los que "el hombre despliega sentidos" y "la obra los desborda", haciendo de aquella forma un auténtico "arte viviente". Allí se tejen diversos niveles del mundo, desprovistos de sus estructuras y funciones habituales, entreverados en otras relaciones que posibilitan formas privilegiadas de experiencia. Su finalidad radica en sí misma, en dicho proceso de creación por parte del autor o de re-creación por parte de su receptor en cuanto acercamiento a otro modo de vida. En clave antropológica, mediante la creación de ámbitos en tanto experiencia cualitativa que valora ciertos aspectos del mundo, el hombre establece una relación de interioridad con lo real, con su verdad plena de sentido, al tiempo que el mundo revela modos de ser inexplorados. Esto instituye tanto la ética como la estética, pues estas corresponden a "dos vertientes de una misma realidad: la personalidad humana en su proceso de despliegue" (López Quintás, 1991, p. 226), ya que es en ese salto fuera de sí en el que el hombre construye lo que le es significativo desde su sensibilidad (estética), para consolidarlo como valor y desde allí orientar su existencia (ética).

Siguiendo a Baumgarten (2012), fundador de la estética como disciplina, esta verdad que se crea no es la verdad de los "hechos objetivos" sino la exploración de "otro mundo" como invención verdadera, basándose en los detalles, en las contingencias de cada existencia, en las experiencias individuales; enfocando o sugiriendo esos aspectos cotidianos que no se perciben en el encuadre de lo habitual, pero que para alguien resultan significativos. En este contexto, la verdad literaria significa conocimiento sobre la complejidad de la vida humana, tal como lo han planteado Compagnon (2012), Lotman (2011), Todorov (2009), Kundera (2007), Cárdenas (2004; 2009), entre otros.

[...] al ser lo propio de la literatura el análisis de las relaciones siempre particulares que ponen en relación las creencias, las emociones, la imaginación y la acción, contiene un conocimiento insustituible, detallado y no resumido, sobre la naturaleza humana, un conocimiento de las singularidades (Compagnon, 2012, p. 58).

Aunque podría objetarse por qué no ir directamente a los hechos, sin recurrir a los rodeos literarios o a las nimiedades de una vida en particular, con el fin de conocer lo que es el ser humano, resulta que su singularidad como persona se construye solo de lo que a cada quien acontece en su existencia, en su propia experiencia, como devenir.

Esta creación alternativa nacida del interior de la persona conlleva entonces un potencial formativo que permite su realización, tal como advirtiera Schiller en sus Cartas sobre la educación estética del hombre: "lo único que consigue la cultura estética es que el hombre, por naturaleza, pueda hacer de sí mismo lo que quiera, devolviéndole así por completo la libertad de ser lo que ha de ser" (1990, p. 23). Según este autor, el hombre siempre se encuentra coaccionado por dos impulsos propios de su naturaleza: uno sensible, material, variable, físico, propio del momento y la necesidad, nacido del sentimiento en el marco de las leyes naturales y otro formal, abstracto, racional, generalizable, invariable y moral, regido por el entendimiento, en el marco de las leyes racionales. Para conciliarlos, cada persona posee una facultad estética basada en un tercer impulso: el del juego, que es la única manera en la que el hombre se constituye como hombre, en su encuentro con la belleza, que no es el mundo como tal ni es solamente una forma idealizada, sino que media entre aquella objetividad y tal subjetividad. Dicho estado intermedio de libertad no influye directamente en el saber ni en la manera de ser de la persona, pero se instituye como "condición necesaria para llegar a un conocimiento y a una manera de ser y pensar" 
en tanto concilia los otros dos impulsos. Y es gracias a este "desinterés", ya planteado por Kant (2003), que la estética - al igual que la Bildung - supera las necesidades básicas y el sentido de lo útil, para relacionarse con el juego, como fin en sí mismo, armonizando el espíritu del hombre.

\section{Conclusiones}

Un proceso de formación (Bildung) que permita a cada persona realizarse desde su verdad singular se basa en el despliegue de su facultad estética, libre de todo interés externo, que le concede un modo particular de construir significativamente ámbitos de la realidad: su realidad. Para llevar esto a la acción educativa, según el carácter práctico de la antropología pedagógica, la creación literaria se presenta como un escenario que propicia tal construcción de sentidos no solo basados en experiencias vitales fácticas, sino en el intento de crear otros mundos posibles. De esta manera, el camino en que cada persona "llega a ser lo que es" se enriquece experimentando lo que aún no ha sido, lo que solo es en potencia, lo que quizá nunca sea, lo que podría llegar a ser.

Por esta razón, la formación (Bildung) literaria basada en la escritura de ficción se plantea como una alternativa para la didáctica de la literatura que permite a los estudiantes desbordar sentidos desde el despliegue personal y, conocer en su uso, gramáticas y estrategias de creación. Así responde, antropológicamente, al rasgo distintivo creador del hombre (poiesis) abordado desde las posibilidades de realidad que le confiere el poder inventivo del lenguaje. En cuanto a lo pedagógico, a la trascendencia formativa de lo literario en la realización personal desde las potencias de vida encarnadas en una concepción amplia de ficción. En cuanto a la didáctica de la literatura, a esa aparición minoritaria de la creación literaria en la escuela, renovando su valor estético para generar una versión alternativa de lo real.

\section{Referencias}

Aguiar, V. (2011). Teoría de la literatura. Madrid: Gredos. Alvarado, M., Rodríguez, M y Tobelem, M. (1981). Teoría y práctica de un taller de escritura. Madrid: Altalena.

Alvarado, M. (2013). Escritura e invención en la escuela. Buenos Aires: Fondo de Cultura Económica.

Aristóteles. (2007). Arte poética/Arte retórica. México: Porrúa.

Ballester, J. (2015). La formación lectora y literaria. Barcelona: GRAó.

Baquero, P. (2015). Didáctica de la literatura: interdisciplina y sospecha. En C. Guevara. Enseñanza de la literatura: perspectivas contemporáneas (pp. 29-48). Bogotá: Universidad Distrital Francisco José de Caldas.

Bárcena, F. y Mèlich, J. (2014). La educación como acontecimiento ético. Natalidad, narración y hospitalidad. Buenos Aires: Miño y Dávila.

Barrio, J. (2010). Elementos de antropología pedagógica. Madrid: RIALP.

Baumgarten, A. (2012). De la belleza del pensar a la belleza del arte. Santiago: Universidad Católica de Chile.

Béguin, A. (1997). Creación y destino I. México: Fondo de Cultura Económica.

Bierwisch, M. (1965). Poetics and Linguistics. En D. Freeman. Linguistic and Literary Style (pp. 96-115). New York: Rinhehart and Winston.

Cárdenas, A. (2004). Elementos para una pedagogía de la literatura. Bogotá: Universidad Pedagógica Nacional.

Cárdenas, A. (2009). Literatura, pedagogía y formación en valores. Enunciación, 2(14), 5-20.

Colomer, T. (1991). De la enseñanza de la literatura a la educación literaria. Comunicación, lenguaje y educación, 9, 21-31.

Colomer, T. (2010a). La didáctica de la literatura: temas y líneas de investigación e innovación. En Biblioteca virtual universal. Recuperado de http://www.biblioteca. org.ar/libros/155187.pdf.

Colomer, T. (2010b). La evolución de la enseñanza literaria. En Biblioteca virtual universal. Recuperado de http://biblioteca.org.ar/libros/155227.pdf

Compagnon, A. (2012). ¿Para qué sirve la literatura? Barcelona: Acantilado. 
Currea, S. et ál. (2017). Estado de arte sobre la relación entre creación literaria y formación humana en trabajos de investigación referidos a la educación secundaria. Universidad de San Buenaventura (tesis de Especialización, sin publicar).

Delmiro, B. (1995). El aprendizaje de la escritura literaria. La educación literaria. Textos de Didáctica de la lengua $y$ de la literatura, 4, 57-66.

Delmiro, B. (2002). La escritura creativa en las aulas. En torno a los talleres literarios. Barcelona: GRAÓ.

Demetrio, D. (1999). Escribirse. La autobiografía como curación de uno mismo. Barcelona: Paidós.

Dueñas, J. (2013). La educación literaria. Revisión teórica y perspectivas de futuro. Didáctica. Lengua y literatura, 25, 135-156.

Eagleton, T. (2002) Una introducción a la teoría literaria. México: Fondo de Cultura Económica.

Eco, U. (1994). Introducción. En M. Serafini. Cómo se escribe. Barcelona: Paidós.

Fabre, M. (2011). Experiencia y formación: la Bildung. Revista Educación y Pedagogía, 23, 59, 215-225.

Ferrer, E. (2000). Literatura y teoría literaria: el ser como construcción simbólica. Papeles, 5, 7-17.

Frugoni, S. (2006). Imaginación y escritura. La enseñanza de la escritura en la escuela. Buenos Aires: Libros del Zorzal.

Garcés, J. y Runge, A. (2011). Educabilidad, formación y antropología pedagógica: repensar la educabilidad a la luz de la tradición pedagógica alemana. Revista Científica Guillermo de Ockham, 9 (2), 13-25.

Garrido, M. (2000). Nueva introducción a la teoría de la literatura. Madrid: Síntesis.

González, M. y Caro, M. (2009). Didáctica de la literatura. La educación literaria. En Digitum. Universidad de Murcia. Recuperado de https://digitum.um.es/xmlui/ bitstream/10201 /7791/7/didactica_de_la_literatura_-_educacion_literaria.ps

Hamman, B. (1992). Antropología pedagógica. Introducción a sus teorías, modelos y estructuras. Madrid: Vicens Vives.

Horacio. (2012). Arte poética. Madrid: Cátedra.

Horlacher, R. (2014). Bildung. La formación. Barcelona: Octaedro.

Ipland, J. (1999). El concepto de Bildung en el neohumanismo alemán. Huelva: Hergué.
Jaramillo, J. y Manjarrés, E. (1998). Pedagogía de la escritura creadora: minicuento, diario, imagen poética, hakú. Bogotá: Magisterio.

Kant, I. (2003). Crítica del juicio. México: Porrúa.

Kant, I. (2008). Sobre pedagogía. Córdoba: Encuentro.

Kayser, W. (1992). Interpretación y análisis de la obra literaria. Madrid: Gredos.

Klafki, W. (1991). Sobre la relación entre didáctica y metódica. Educación y pedagogía, 5, 85-108.

Klafki, W. (1986). Los fundamentos de una didáctica crítico-constructivista. Revista de Educación, 280, 37-80.

Kohan, S. (2002). Escribir sobre uno mismo. Todas las claves para dar forma literaria al material biográfico. Barcelona: Alba.

Kundera, M. (2007). El arte de la novela. Barcelona: Tusquets.

Larrosa, J. (2013). La experiencia de la lectura. Estudios sobre literatura y formación. México: Fondo de Cultura Económica.

Llovet, J.; Caner, R.; Quiroga, N. y Monteverde, A. (2012). Teoría literaria y literatura comparada. Barcelona: Ariel.

Londoño, E. (2010). La producción de sentido en la experiencia pedagógica. Itinerario educativo, 55, 39-63.

López Quintás, A. (1991). La experiencia estética y su poder formativo. Navarra: Verbo Divino.

López Quintás, A. (2000). La experiencia estética, fuente inagotable de formación humana. Aisthesis, 33, 17-34.

Lotman, Y. (2011). Estructura del texto artístico. Madrid: Akal.

Marías, J. (1995). Lo que no sucede y sucede. En El país. Recuperado de http://elpais.com/diario/1995/08/12/ cultura/808178408_850215.html

Martínez, Z. y Murillo, A. (2013). Concepciones de la didáctica de la literatura en Colombia durante los últimos diez años. Grafía, 10(1), 175-194.

Mendoza, A. (2006). La educación literaria, bases para la formación de la competencia lecto-literaria En: Biblioteca virtual universal. Recuperado de http:// www.biblioteca. org.ar/libros/300233.pdf.

Ministerio de Cultura. (2011). Guía para talleres de escritura creativa. Creación y planeación. Bogotá, Taller de edición Rocca. 
Nietzsche, F. (2002). La gaya ciencia. Madrid: Edaf.

Nussbaum, M. (2005). El cultivo de la humanidad: una defensa clásica de la reforma en la educación liberal. Madrid: Paidós.

Pampillo, G. (1982). El taller de escritura. Buenos Aires: Plus ultra.

Paz, O. (2005). El arco y la lira. El poema, la revelación poética. Poesía e historia. México: Fondo de Cultura Económica.

Quintana, J. (1986). El concepto de Bildung en el pensamiento alemán. Análisis pedagógica. Il singnificato delleducatione, 2, 6-17.

Reyes, A. (2005). Teoría literaria. México: Fondo de Cultura Económica.

Runge, A. (2008). Ensayos sobre pedagogía alemana. Bogotá: UPN.

Rodari, G. (2005). Gramática de la fantasía. Bogotá: Panamericana.

Rosenblatt, L. (2002). La literatura como exploración. México: Fondo de Cultura Económica.

Saavedra, S. (2011). La creación literaria en el ámbito educativo: de la estructura superficial a la construcción narrativa de la realidad. Lenguaje, 37, 395-417.

Saavedra, S. (2013). Hacia una evaluación formativa, crítica y artística de la creación literaria. Folios, 37, 167-183.
Saavedra, S. (2017). Formación (Bildung) y creación literaria. "Llegar a ser lo que se es" en diversos mundos posibles. La palabra, 31, 197-210.

Sábato, E. (2014). El escritor y sus fantasmas. Barcelona: Seix Barral.

Schaeffer, J. M. (2013). Pequeña ecología de los estudios literarios. ¿Por qué y cómo estudiar la literatura? Buenos Aires: Fondo de Cultura Económica.

Schiller, F. (1990). Kallias: Cartas sobre la educación estética del hombre. Barcelona: Antrophos.

Todorov, T. (2009). La literatura en peligro. Barcelona: Círculo de lectores-Galaxia Gutenberg.

Vargas, L. (2011). El taller de escrituras creativas: historia, conceptualización y propuestas. Ibagué: Universidad del Tolima.

Vargas Guillén, G., Gamboa, S. y Reeder, H. (2010). La humanización como formación. La filosofía y la enseñanza de la filosofía en la condición postmoderna. Bogotá: San Pablo.

Vargas Llosa, M. (1998). Cartas a un joven novelista. Bogotá: Planeta.

Warning, R. (ed.). (1989). Estética de la recepción. Madrid: Visor.

Warren, A. y Wellek, R. (2009). Teoría literaria. Madrid: Gredos. 